\title{
Diode Laser-assisted Lingual Frenectomy: A Case Series
}

\author{
'Zeba Jafri, ${ }^{2}$ Nafis Ahmad, ${ }^{3}$ Nishat Sultan, ${ }^{4}$ Ashu Bhardwaj
}

\begin{abstract}
A short or thick and fibrotic lingual frenum results in ankyloglossia or tongue-tie. Restricted tongue movement in ankyloglossia may at times result in speech problem with difficulty in pronunciation of some sounds, impaired mechanical cleaning of the oral cavity by free tongue movement, gingival recession or malocclusion. Thus, the surgeries for ankyloglossia can be considered at any age depending upon patient's history of speech, mechanical and social difficulty and can be performed by scalpel, electrocautery or lasers nowadays. The paper presents report of three cases where diode laser has been used for lingual frenectomy. Diode laser has shown to be one of the excellent options for performing these surgeries with better bleeding control, excellent precision, less discomfort and short healing time.
\end{abstract}

Keywords: Ankyloglossia, Diode laser, Frenectomy.

How to cite this article: Jafri Z, Ahmad N, Sultan N, Bhardwaj A. Diode Laser-assisted Lingual Frenectomy: A Case Series. Int J Laser Dent 2014;4(3):87-90.

Source of support: Nil

Conflict of interest: None

\section{INTRODUCTION}

Lingual frenum is a fold of mucous membrane that attaches tongue to the floor of mouth. When this frenum is short or encloses muscle fibers with it, making it thick and fibrotic, it can result in ankyloglossia or also known as tongue-tie.

The term ankyloglossia comes from the Greek word meaning ankylos, i.e. 'crooked' and glossa, i.e. 'tongue'. It was first used in the medical literature in 1960s when Wallace defined tongue-tie as a condition in which the tip of the tongue cannot be protruded beyond the lower incisor teeth because of a short frenulum linguae, often containing scar tissue. ${ }^{1}$

\footnotetext{
${ }^{1-3}$ Assistant Professor, ${ }^{4}$ Professor

${ }^{1}$ Department of Periodontology, Faculty of Dentistry, Jamia Millia Islamia University, New Delhi, India

${ }^{2}$ Department of Prosthodontics, Jamia Millia Islamia University New Delhi, India

${ }^{3,4}$ Department of Periodontology, Jamia Millia Islamia University, New Delhi, India
}

Corresponding Author: Zeba Jafri, Assistant Professor Department of Periodontology, Faculty of Dentistry, Jamia Millia Islamia University, New Delhi, India, Phone: 9990847379 e-mail: zebaperio@yahoo.co.in
Later, Kotlow ${ }^{2}$ classified ankyloglossia depending on the range of free tongue as follows:

- Class I: Mild with 12 to $16 \mathrm{~mm}$ of free tongue

- Class II: Moderate with 8 to $11 \mathrm{~mm}$ of free tongue

- Class III: Severe with 3 to $7 \mathrm{~mm}$ of free tongue

- Class IV: Complete with $<3 \mathrm{~mm}$ of free tongue

Various surgical techniques like frenotomy, frenectomy and frenuloplasty over time have been used for treating ankyloglossia. These procedures were conventionally carried out by scalpel only, until electrocautery and later lasers were introduced. Use of electrocautery was considered better than the use of scalpel for these surgical techniques in terms of hemostasis but the primary mode of tissue interaction with electrosurgical instruments is by heat ablation that produced a zone of necrosis. As frenectomy with diode lasers is known to have several advantages over scalpel and electrosurgical procedures this technique is more preferred nowadays.

The present paper involves report of three cases where a diode laser AlGaAs (Denlase $810 \mathrm{~nm}$ ) has been used for lingual frenectomy.

\section{CASE REPORTS}

\section{Cases 1 and 2}

A 24-year-old male patient (case 1) and a 20-year-old female patient (case 2) reported to the department of periodontics with a complaint of difficulty in complete protrusion of tongue and slight impairment of speech. Their eye, nose and throat (ENT) and physical examination were normal. On intraoral examination, the case 1 (Fig. 1A) was diagnosed with class II ankyloglossia using Kotlow assessment with fibrotic and thick frenum, while case 2 (Fig. 2A) was diagnosed with class III ankyloglossia. Both had restricted protusion of tongue with slight midline invagination of tongue on protrusion. There was neither any gingival recession in relation to mandibular incisors lingually nor any malocclusion present in either of the patients. Case 1 had shown more difficulty in speech like to roll an ' $r$ ' or to sound some consonants like ' $t$ and $n$ ' than the case 2 although the length of the free tongue for case 2 was comparatively shorter. After thorough examination, lingual frenectomy with diode laser was planned for both the patients. 


\section{Case 3}

A 58-year-old male geriatric patient visited to the department of prosthodontics with complaint of missing teeth and wanted fabrication of partial denture for the same. He gave a dental history of previously made partial denture, upper of which he was carrying and wore occasionally but had misplaced his lower partial denture complaining of never wearing it as it was ill fitted. On examination, patient had partially edentulous upper and lower arch. The lingual frenum in his lower arch had high attachment on to the alveolar ridge (Fig. 3A) which probably seemed to be due to the resorption of alveolar ridge. Considering it to be one of the local anatomic factors which could have resulted in previous ill fitting denture, a preprosthetic surgery of lingual frenectomy was planned before making another partial denture and patient was referred to the department of periodontics.

\section{Surgical Procedure}

Lingual frenectomy by soft-tissue laser was carried out for each patient after the informed consent was taken. $0.6 \mathrm{ml}$ of lignocaine was injected in the frenum. Diode laser with delivered optical power of $3.9 \mathrm{~W}$ maximum, with an initiated fiberoptic tip of $400 \mu \mathrm{m}$ in pulse mode with pulse length $100 \mu \mathrm{sec}$ and pulse interval of $200 \mu \mathrm{sec}$ delivering an average power of $1.3 \mathrm{~W}$ (Fig. 4) was used for lingual frenectomy.

The tongue was held backward and the diode laser was applied in a contact mode with focused beam for excision of tissue. The tip of laser was moved from apex to base of frenum in brushing method excising it slowly (Figs 2B and 3B) and continuously mopping with wet gauze preventing excessive thermal damage to the excised tissue. A diamond-shaped wound appeared after excision (Fig. 1B), and protrusive tongue movement was checked postoperatively. There was minimal bleeding and suturing was not required. Patient was given analgesics and recalled after 1 week (Figs $1 \mathrm{C}$ and 2C) and 1 month (Fig. 1D). Healing was uneventful and the protrusion of tongue improved in cases 1 and 2 which were later referred to speech therapist. Case 3 was referred back to the department of prosthodontics for fabrication of partial denture after uneventful healing of the tissues (Fig. 3C).

\section{DISCUSSION}

Restricted tongue movement in ankyloglossia may cause speech difficulty for pronunciation of dentolingual-labial sounds. Consonants, like $\mathrm{t}, \mathrm{d}, \mathrm{n}$ and, 1 , are difficult to
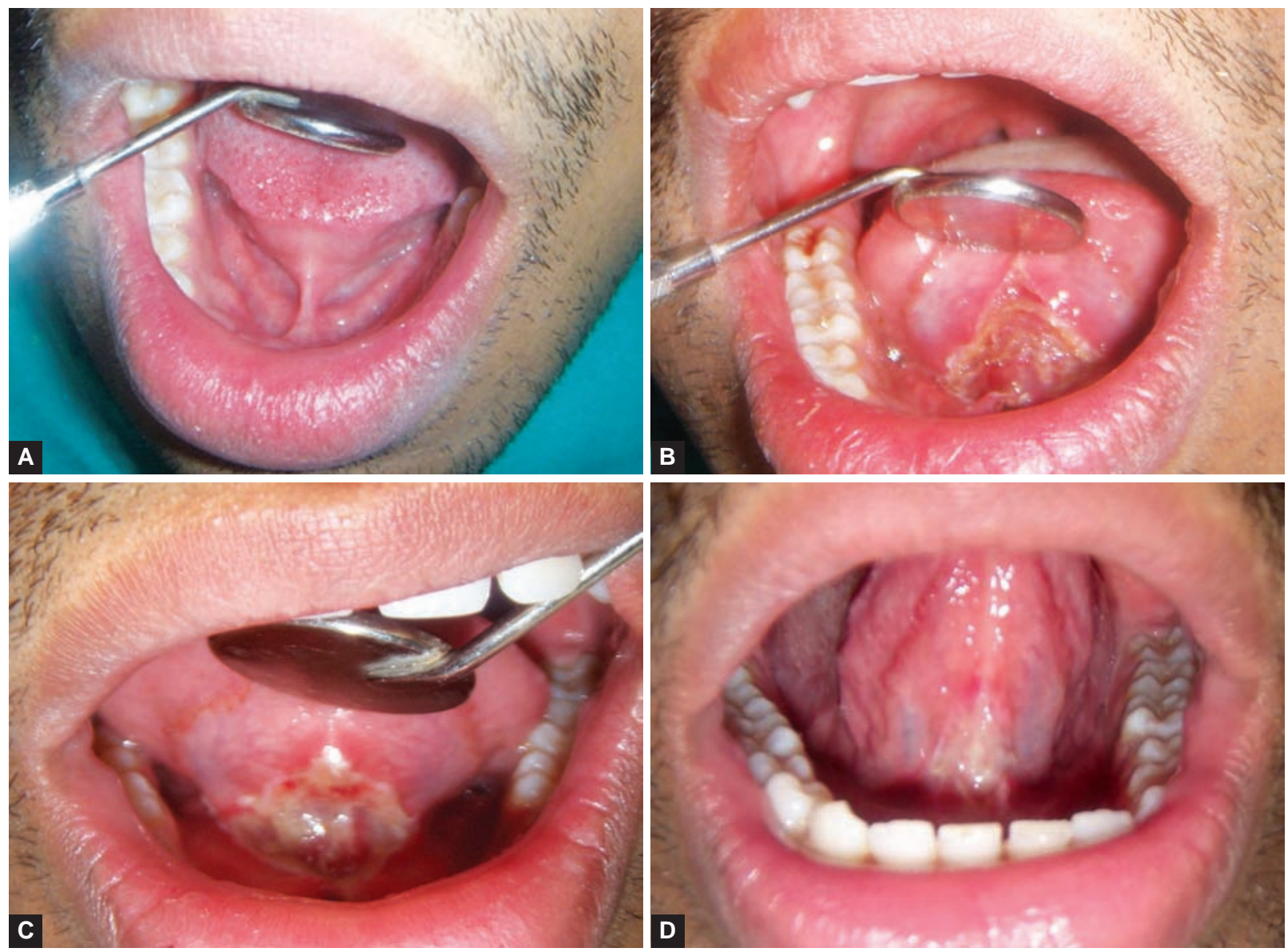

Figs 1A to D: (A) Case 1-preoperative (Kotlow's class II ankyloglossia), (B) case 1-intraoperative,

(C) case 1-postoperative 7 days and (D) case 1-postoperative 1 month 

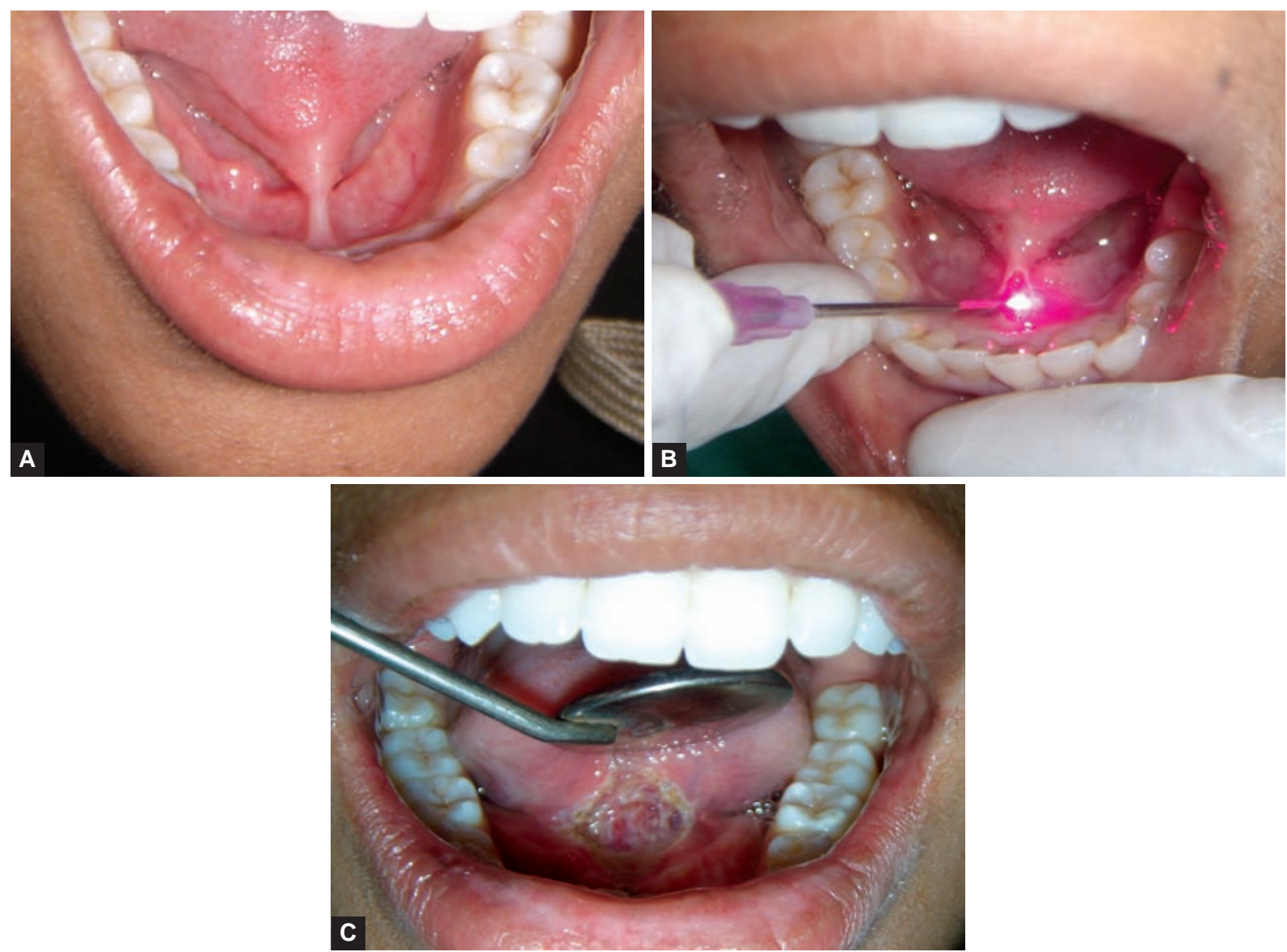

Figs 2A to C: (A) Case 2-preoperative (Kotlow's class III ankyloglossia), (B) case 2-intraoperative and (C) case 2-postoperative
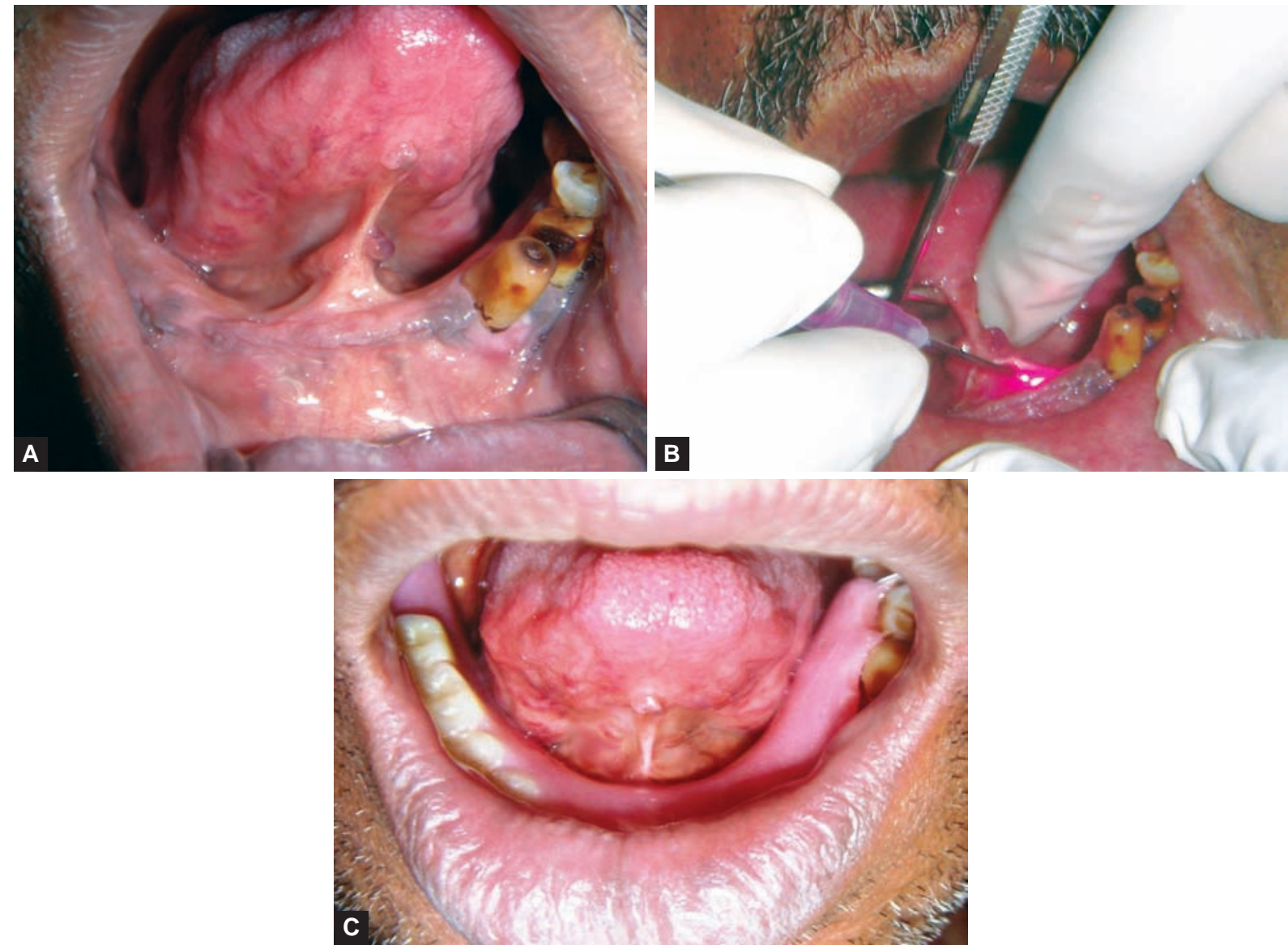

Figs 3A to C: (A) Case 3-preoperative, (B) case 3-intraoperative, (C) case 3-postoperative 


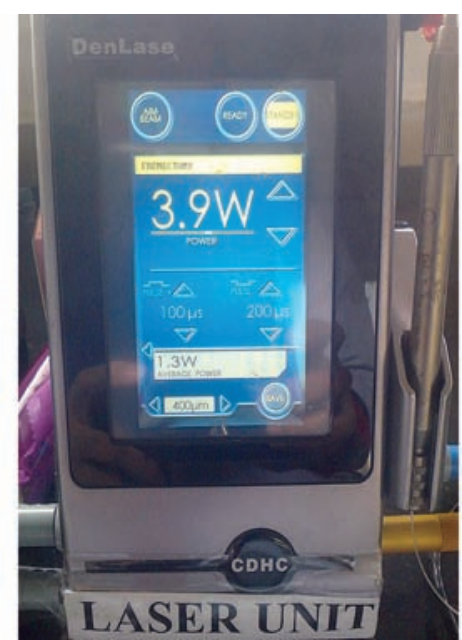

Fig. 4: Diode laser unit with specification used during frenectomy

pronounce and frontal and lateral lisping may be seen. Tongue-tie has also been associated with problems like malocclusion and gingival recession. ${ }^{3}$ Besides this, tongue also helps in cleaning the oral cavity by its free movement in sweeping of insides of cheeks, fronts and backs of teeth and licking right around both lips. The surgeries for ankyloglossia can be considered at any age depending upon patient's history of speech, mechanical and social difficulty. ${ }^{4}$

Diode lasers have wavelengths ranging from 655 to $980 \mathrm{~nm}$. Laser light is monochromatic, coherent and collimated, therefore, it delivers a precise burst of energy to the targeted area. Diode lasers can be used in continuous waves or gated pulse modes in contact or out of contact with the tissue. Pulsed mode provides time for the tissues to cool down and prevents the collateral tissue damage incident to excessive heat production. ${ }^{5}$ Laser energy incises tissue more efficiently than the scalpel, generates complete vaporization and coagulates blood vessel. The hemostatic effect is created when laser energy interacts with the soft tissue is due to the sealing of capillaries ${ }^{6}$ by protein denaturation and stimulation of clotting factor VIII production. The excellent hemostasis, and absence of postoperative swelling was attributed to increased platelet activation by lasers ${ }^{7}$ and sealing of lymphatic vessels. ${ }^{8}$ As a result of improved hemostasis, the surgical field remains clean improving visualization of surgical site which can be left without sutures. Examined histologically, laser wounds have been found to contain significantly lower number of myofibroblasts. ${ }^{9}$ This results in less wound contraction and scarring, ultimately improved healing. In addition, sterilization of wound ${ }^{10}$ by laser reduces the need for postoperative care and antibiotics. $^{5}$

\section{CONCLUSION}

The use of diode laser in oral surgical procedures is beneficial for both the clinician and the patient. Laserassisted lingual frenectomy is easy to perform with excellent precision, less discomfort, short healing time, better postoperative pain perception and can be left without sutures because of excellent hemostasis.

\section{REFERENCES}

1. Wallace AF. Tongue-tie. Lancet 1963 Aug;2(7304):377-378.

2. Kotlow L. Ankyloglossia (tongue-tie): a diagnostic and treatment quandary. Quintessence International 1999; 30(4): 259-262.

3. Ewart NP. A lingual mucogingival problem associated with ankyloglossia: a case report. NZ Dent J 1990 Jan;86(383):16-17.

4. Messner AH, Lalakea ML. Ankyloglossia: controversies in management. Int J Pediatr Otorhinolaryngol 2000 Aug; 54(2):123-131.

5. Kotlow L. Laser in pediatric dentistry. Dent Clin North Am 2004;48(4):889-922.

6. Pirnat S. Versality of an $810 \mathrm{~nm}$ diode laser in dentistry: an overview. J Laser Health Acad 2007;4(2):1-9.

7. Mordon S, Begu S, Buys B, et al. Study of platlets in vivo after endothelial stimulation with laser irradiation using fluorescence in trivital videomicroscopy PEGylated liposome staining. Microvasc 2002;64(2):316-325.

8. Pick RM, Pecaro BC, Silberman CJ. The laser gingivectomy: the use of $\mathrm{CO}_{2}$ laser for the removal of phenytoin hyperplasia. J Periodontol 1985 Aug;56(8):492-496.

9. Zeinoun T, Nammour S, Dourov N, et al. Myofibroblasts in healing laser excision wounds. Lasers Surg Med 2001;28(1): 74-79.

10. Moritz A, Schoop U, Goharkhay K, Schauer P, Dourtbudak O, Wernisch J, Sperr W. Treatment of periodontal pockets with a diode laser. Lasers Surg Med 1998;22(5):302-311. 